\title{
Consensus Reached on How to Recognise and Manage Sepsis and Septic Shock by Intensivists in Northeast Nigeria Held at the University of Maiduguri Teaching Hospital, Borno State Nigeria
}

\section{Adamu A Sadiq ${ }^{1}$, Ballah Abubakar ${ }^{*}$, Shehu U Panda ${ }^{3}$, Hassan MA ${ }^{4}$, Buma GB ${ }^{5}$, Dakum Longji', Jimoh L Mufutau ${ }^{1}$ and Alfa Ndakotsu}

\author{
${ }^{1}$ Department of Anaesthesia and ICU, University of Maiduguri Teaching Hospital, Borno State, Nigeria \\ ${ }^{2}$ Department of Anaesthesia and ICU, Atbu Teaching Hospital, Bauchi State, Nigeria \\ ${ }^{3}$ Department of Anaesthesia and ICU, Federal Teaching Hospital, Gombe State, Nigeria \\ ${ }^{4}$ Department of Anaesthesia and ICU, Federal Medical Centre, Yola, Adamawa State, Nigeria \\ ${ }^{5}$ Department of Anaesthesia and Critical Care, Federal Medical Center, Jalingo, Taraba State, Nigeria \\ ${ }^{6}$ Department of Hospital Services, Federal Ministry Of Health, Abuja, Nigeria \\ ${ }^{7}$ Department of Anaesthesia and ICU, Federal Medical Center Nguru, Yobe State, Nigeria
}

*Corresponding author: DR. Abubakar Ballah, Department of Anaesthesia And ICU, Atbu Teaching Hospital, Bauchi, Hospital Road Off Yandoka Road, Pmb 0011 Bauchi State, Nigeria

\begin{abstract}
Worldwide, sepsis is a serious health threat and is among the leading cause of death in patients admitted into Intensive Care Units in hospitals across Nigeria and northeastern Nigeria, in particular. Patients of all sexes and ages are affected. However, the vulnerable groups such as extremes of ages (neonates and elderly), pregnant women, the immune-compromised, and those with underlying chronic medical conditions are more at risk. As a low income country, sepsis is a major burden to our health care system in terms of morbidity, mortality and financial cost. The consensus reached focused on early recognition of sepsis and initiating early management which is the mainstay in ensuring survival and reducing the financial burden on patients and the health system. This consensus is based on current updates in the management of sepsis.
\end{abstract}

\section{Introduction}

Over the years, the management of sepsis has evolved due to better understanding of the pathophysiology, etiology and clinical course of the disease. In 1991, the sepsis-1 consensus was developed based on the severe inflammatory response syndrome (SIRS) criteria. The SIRS criteria looked at four parameters: Temperature $>38^{\circ} \mathrm{C}$ or $<36^{\circ} \mathrm{C}$, Respiratory rate $>20$ breaths per minute, Heart rate $>90$ beats per minute, White blood cell count of $>12 \times 109 /$ L or $<4 \times 109 / \mathrm{L}$ [1]. Also in the sepsis-1 definition, severe sepsis was described as sepsis complicated by organ dysfunction. However, what constitute organ dysfunction was not defined. This led to revision of the sepsis-1 in 2001 and severe sepsis was replaced with sepsis with organ dysfunction. Organ dysfunction includes systolic blood pressure $(\mathrm{SBP})<90 \mathrm{mmHg}$ or mean arterial pressure $<65 \mathrm{mmHg}$ or serum lactate $>2.0 \mathrm{mmol} / \mathrm{L}$ after initial fluid challenge, urine output $<0.5 \mathrm{ml} / \mathrm{kg} / \mathrm{hr}$ for 2 hours, creatinine $>177 \mu \mathrm{mol} / \mathrm{l}$, platelets $<100 \times 109, \mathrm{SPO}_{2}<$ $90 \%$ on room air, Bilirubin $>34 \mu \mathrm{mol} / \mathrm{L}$, International normalized ratio (INR) $>1.5$ or a PTT $>60$ seconds. It was termed sepsis-2 [2]. In 2016, sepsis-3 was

Citation: Sadiq AA, Abubakar B, Panda SU, Hassan MA, Buma GB, et al. (2021) Consensus Reached on How to Recognise and Manage Sepsis and Septic Shock by Intensivists in Northeast Nigeria Held at the University of Maiduguri Teaching Hospital, Borno State Nigeria. Int J Anesthetic Anesthesiol 8:128. doi. org/10.23937/2377-4630/1410128

Accepted: December 02, 2021: Published: December 04, 2021

Copyright: (c) 2021 Sadiq AA, et al. This is an open-access article distributed under the terms of the Creative Commons Attribution License, which permits unrestricted use, distribution, and reproduction in any medium, provided the original author and source are credited. 
Table 1: Sequential (Sepsis-related) Organ Failure Assessment Score (SOFA).

\begin{tabular}{|c|c|c|c|c|c|}
\hline System & 0 & 1 & 2 & 3 & 4 \\
\hline \multicolumn{6}{|l|}{ Respiratory } \\
\hline $\mathrm{PaO}_{2} / \mathrm{FiO}_{2}, \mathrm{mmHg}$ & $\geq 400$ & $<400$ & $<300$ & $<200$ with respiratory & $<100$ with respiratory support \\
\hline \multicolumn{6}{|l|}{ Cardiovascular } \\
\hline $\mathrm{MAP}, \mathrm{mmHg}$ & $\geq 70$ & $<70$ & & & \\
\hline $\begin{array}{l}\text { Catacholamine dose, } \\
\mu \mathrm{g} / \mathrm{kg} / \mathrm{min}\end{array}$ & & & $\begin{array}{l}\text { Dopamine } \leq \\
5 \text { or any dose } \\
\text { Dobutamine }\end{array}$ & $\begin{array}{l}\text { Dopamine }>5 \\
\text { Epinephrine } \leq 0.1 \\
\text { Norepinephrine } \leq 0.1\end{array}$ & $\begin{array}{l}\text { Dopamine }>15 \text { or } \\
\text { Epinephrine }>0.1 \text { or } \\
\text { Norepinephrine }>0.1\end{array}$ \\
\hline \multicolumn{6}{|l|}{ Renal } \\
\hline Creatinine, $\mu \mathrm{mol} / \mathrm{L}$ & $<110$ & $110-170$ & $171-299$ & $300-440$ & $>440$ \\
\hline Urine output, $\mathrm{ml} / \mathrm{day}$ & & & & $<500$ & $<200$ \\
\hline \multicolumn{6}{|c|}{ Central Nervous System } \\
\hline GCS & 15 & $13-14$ & $10-12$ & $6-9$ & $<6$ \\
\hline \multicolumn{6}{|l|}{ Liver } \\
\hline Bilirubin, $\mu \mathrm{mol} / \mathrm{L}$ & $<20$ & $20-32$ & 33-101 & $102-204$ & $>204$ \\
\hline \multicolumn{6}{|l|}{ Coagulation } \\
\hline Platelets, x109/L & $\geq 150$ & $<150$ & $<100$ & $<50$ & $<20$ \\
\hline
\end{tabular}

GCS, Glasgow Coma Scale, MAP, mean arterial pressure.

Table 2: quick Sequential (Sepsis-related) Organ Failure Assessment Score (qSOFA).

\begin{tabular}{|l|l|}
\hline System & \\
\hline Respiratory & Respiratory rate $\geq 22 / \mathrm{min}$ \\
\hline Cardiovascular & SBP $<100 \mathrm{mmHg}$ \\
\hline Central Nervous & $\begin{array}{l}\text { Altered mentation } \\
\text { GCS } \leq 13\end{array}$ \\
\hline
\end{tabular}

developed and was defined as "life-threatening organ dysfunction caused by a dysregulated host response to infection". Diagnosing sepsis here is based on presence of an infection and a change in the [sepsis-associated] Sequential Organ Failure Assessment (SOFA) score of two points or more for patients in an Intensive Care Unit (ICU). SOFA is a mortality prediction score that is based on the degree of dysfunction of six (6) organ systems namely; Respiratory, Cardiovascular, Renal, Central Nervous System, Hepatobiliary and Haematological system. It is based on laboratory result and clinical data. The score is calculated at admission and every 24 hours until discharge using the worst parameters measured during the prior 24 hours. The quick SOFA (qSOFA) is a bedside tool used to rapidly identify adult patients with infection who are more likely to have poor outcome; score of two or more for patients outside of the ICU. A pneumonic "HAT" makes it easier to remember the qSOFA (Hypotension: SBP $\leq 100 \mathrm{mmHg}$, Altered mental status: GCS < 15 and Tachypnoea: Respiratory Rate $\geq 22$ ). The new definition is intended to improve the clarity of the definitions for clinical care, epidemiology, quality improvement and research [3].

\section{Definition}

Sepsis is defined as 'life threatening organ dysfunction caused by dysregulated host response to infection'. The clinical diagnosis of sepsis is based on a patient having infection and a raised Sequential (Sepsisrelated) Organ Failure Assessment Score (SOFA) of two points or more for patients in an ICU (Table 1) and a quick SOFA (qSOFA) score of two or more for patients outside of the ICU (Table 2) [3].

Septic shock-Circulatory, cellular, and metabolic abnormalities in septic patients, presenting as fluidrefractory hypotension requiring vasopressor therapy with associated tissue hypoperfusion (lactate $>2$ $\mathrm{mmol} / \mathrm{L})$. Septic shock is diagnosed if a patient requires vasopressor to maintain a MAP of $>65 \mathrm{mmHg}$ and a serum lactate level $>2 \mathrm{mmol} / \mathrm{L}$ in the absence of hypovolaemia $[4,5]$.

\section{Early Warning Scores}

Early warning score (EWS) is a guide used by clinicians to quickly determine the degree of illness of a patient and to predict patients likely to deteriorate. In sepsis, studies have indicated that patients exhibit signs of increased risk early before deterioration. These EWS such as the Modified Early Warning Score (MEWS), Early warning Scoring System (EWSS), or National Early Warning Score (NEWS), were developed to screen patients at high risk of deterioration. These are screening tools with high sensitivity and their scores are validated tools for predicting poor outcomes [6].

Our forum adopted the NEWS which was developed in 2012 by the Royal College of Physicians as a predictor of patient deterioration. The NEWS has seven parameters namely temperature, systolic blood pressure, respiratory rate, oxygen saturation, oxygen supply, heart rate, and level of consciousness and a total 
Table 3: Parameters.

\begin{tabular}{|l|l|l|l|l|l|l|l|}
\hline Physiological Parameters & 3 & 2 & 1 & 0 & 1 & 2 & 3 \\
\hline Respiratory Rate (BPM) & $\geq 8$ & - & $09-11$ & $12-20$ & - & $21-24$ & $\geq 25$ \\
\hline Oxygen saturation & 94 & $92-93$ & $94-95$ & $\geq 96$ & - & - & - \\
\hline Supplemental Oxygen & - & Yes & - & No & - & - & - \\
\hline SBP & $<90$ & $90-100$ & $101-110$ & $111-219$ & - & - & $\geq 220$ \\
\hline Heart rate & $\leq 40$ & - & $41-50$ & $51-90$ & $91-110$ & $111-130$ & $\geq 130$ \\
\hline Temperature & $<350$ & - & $35.1-36^{\circ}$ & $36.1-38^{\circ}$ & $38.1-39^{\circ}$ & $\geq 39.10$ & - \\
\hline Conscious level & - & - & - & A & - & - & V,P,U \\
\hline
\end{tabular}

A: Alert; U: Unresponsive; P: react to pain; V: loud voice according to AVPU scale.

score of 20. Patients are classified into three categories. Those with low score (NEWS 1-4), medium score (NEWS of 5-6) and high score (NEWS $\geq 7$ ) as shown in (Table 3 ) [7].

\section{Investigating a Septic Patient}

It is important to identify source(s) of infection to enable effective therapy when managing sepsis. It is important to know which samples are appropriate to collect to allow for confirmation of the presence of infection and identify the specific antimicrobial sensitivity for effective therapy. Useful investigations include;

\section{Serum lactate}

Serum lactate is a marker of tissue perfusion. Serum lactate level of $>2 \mathrm{mmol} / \mathrm{L}$ can result from hypoperfusion of organ with or without hypotension. It indicates a poor prognostic factor. A serum lactate level of $\geq 4 \mathrm{mmol} / \mathrm{L}$ indicates septic shock.

\section{Full Blood Count (FBC)}

The clinician can look out for white blood cell (WBC) count (leukocytosis WBC count $>12,000 / \mu \mathrm{L}$ or leukopenia WBC count $<4000 / \mu \mathrm{L}$ ).

\section{Clotting profile}

Coagulation abnormality with INR $>1.5$ or PTT > 60 seconds. The clotting profile also shows thrombocytopaenia with platelets count $<100,000 / \mu \mathrm{L}$.

\section{Culture and sensitivity}

Two sets of blood samples for culture are usually taken to increase the sensitivity for the detection of bacteremia to $90 \%$. Other samples to be collected for culture and sensitivity include cerebrospinal fluid (CSF), urine, stool, sputum or bronchial lavage, swab (wound, vagina etc).

\section{Kidney function}

Acute oliguria (urine output $>0.5 \mathrm{ml} / \mathrm{kg} / \mathrm{hr}$ for at least two (2) hours despite adequate fluid resuscitation, rising levels of urea and creatinine and deranged electrolytes (hyponatremia, hyperkalemia).

\section{Imaging}

Imaging such as X-ray, Ultrasound scan, Computerized tomography of any suspected part of the body can be ordered if the site of infection is not found.

Other supportive investigations include arterial blood gas analysis (arterial hypoxemia $\mathrm{PaO}_{2} / \mathrm{FiO}_{2}$ ratio < $300 \mathrm{mmHg}$, liver function test LFT (hyperbilirubinemia), serum blood glucose (hyperglycemia in the absence of diabetes mellitus), C-reactive protein level of more than two standard deviations above the reference value.

\section{Management of Sepsis}

The major therapeutic goals in the management of sepsis are;

$\checkmark$ To resuscitate patient by improving tissue oxygenation and perfusion,

$\checkmark$ To provide adequate antimicrobial therapy as early as possible with suitable cover against the identified causative organism.

To ensure the organs and systems are functioning adequately and prevent progression to organ dysfunction.

\section{Fluid Resuscitation and Maintaining Tissue Oxygenation and Perfusion}

The use of crystalloid has been advocated in the initial management of sepsis and septic shock. In sepsis, there is vasodilation and capillary leakage there by decreasing the volume of circulation and decrease tissue perfusion. Within the first three (3) hours of resuscitation, $30 \mathrm{ml} /$ $\mathrm{kg}$ of crystalloids should be administered. However response to initial fluid resuscitation should determine how much fluid is given. The clinician should ensure adequate urine output $(0.5 \mathrm{~mL} / \mathrm{kg} / \mathrm{hr})$, mean arterial pressure of $65 \mathrm{mmHg}$, central venous pressure (CVP) of 8-12 $\mathrm{mmHg}$. Fluid overload can result in pulmonary edema, prolonged ICU stay and increased risk of death [3]. For patients who are not managed in the ICU where invasive monitoring may not be available, we recommend strict monitoring of urine output and blood pressure as guide to response to initial fluid resuscitation. 
Table 4: Use of vasopressors.

\begin{tabular}{|l|l|l|l|}
\hline Vasopressor/Inotrope & Dose Range $(\boldsymbol{\mu g} / \mathbf{K g} / \mathbf{M i n})$ & Initial Infusion Rate $(\boldsymbol{\mu g} / \mathbf{K g} / \mathbf{M i n}$ & Bolus Doses $(\mathbf{M g})$ \\
\hline Norepinephrine & $0-40$ & 0.05 & $0.1-0.2$ \\
\hline Epinephrine & $0-20$ & 0.05 & \\
\hline Phenylephrine & $40-180$ & 0.004 U/min & \\
\hline Vasopressin & $0.01-0.06$ & & \\
\hline Milrinone & $0.375-0.75$ & 5 & \\
\hline Dobutamine & $2-20$ & & \\
\hline Dopamine (Low Dose) & $1-4$ & & \\
\hline Dopamine (Medium Dose) & $5-10$ & & \\
\hline Dopamine (High Dose) & $11-20$ & & \\
\hline
\end{tabular}

In critical care settings, vasopressors and inotropes can be used in patients already presenting with pulmonary edema or those who remain unresponsive to initial fluid resuscitation. While vasopressors increase vasoconstriction leading to increased systemic vascular resistance and increased MAP which results in increase perfusion to organs, inotropes help to maintain MAP and tissue perfusion by increasing cardiac contractility. We advocate the use of vasopressors such as norepinephrine as first choice then phenylephrine, epinephrine or vasopressin. Dobutamine and Milrinone are inotropes while Dopamine which is a vasopressor with inotropic properties is dose dependent (Table 4).

\section{Identification of Causative Organism and Appropriate Antimicrobial Therapy}

Early administration of appropriate antibiotic has been advocated and is said to decrease both morbidity and mortality including duration of hospital stay. It has been said that for every hour delay in the administration of antibiotics, the chances of survival is decreased by up to 7.6\% [8]. Clinicians therefore administer based on the knowledge of the likely cause of infection and sensitivity pattern. Sepsis is caused by gram-positive and gramnegative bacteria, anaerobes, fungi and parasites so broad spectrum antibiotics are initially administered based on patient's background which include recent history of exposure to infection, evidence of pertinent colonization, presence of comorbidities, indwelling devices, immunologic status and recent antibiotic exposure in the last 3 months $[9,10]$. Appropriate samples should be collected for microscopy, culture and sensitivity before commencement of antimicrobial therapy.

\section{Recommended Empirical Antibiotics}

\begin{tabular}{|c|c|c|}
\hline Infection & Empirical Therapy & Comment \\
\hline \multicolumn{3}{|l|}{ Respiratory System } \\
\hline Community Acquire Pneumonia & $\begin{array}{l}\text { Combination therapy with a beta-lactam } \\
\text { (ampicillin + sulbactam) and macrolide } \\
\text { (azithromycin, clarithromycin) or beta-lactam } \\
\text { and Fluoroquinolones (levofloxacin) }\end{array}$ & $\begin{array}{l}\text { Risk factors for MRSA, add vancomycin or } \\
\text { linezolid Risk factor Pseudomonas aeruginosa } \\
\text { add piperacillin-tazobactam, cefepime, } \\
\text { meropenem, or imipenem. }\end{array}$ \\
\hline $\begin{array}{l}\text { Hospital Acquired Pneumonia, } \\
\text { Ventilator Acquired Pneumonia }\end{array}$ & $\begin{array}{l}\text { Combination therapy with vancomycin } \\
\text { or linezolid and piperacillin tazobactam, } \\
\text { cefepime, ceftazidime, imipenem, } \\
\text { meropenem }\end{array}$ & $\begin{array}{l}\text { Two anti-pseudomonal antibiotics from } \\
\text { different classes (addition of fluoroquinolones, } \\
\text { aminoglycosides, or polymyxins). }\end{array}$ \\
\hline \multicolumn{3}{|l|}{ Gastrointestinal System } \\
\hline $\begin{array}{l}\text { Commonly Enterobacterales } \\
\text { and Pseudomonas or } \\
\text { Acinetobacter }\end{array}$ & $\begin{array}{l}\text { Broad-spectrum Beta-lactam/Beta-lactamase } \\
\text { inhibitor, combination or a Carbapenem }\end{array}$ & $\begin{array}{l}\text { Empiric therapy should be based on local } \\
\text { microbiological data }\end{array}$ \\
\hline \multicolumn{3}{|l|}{ Genitourinary Tract } \\
\hline Pyelonephritis & $\begin{array}{l}\text { Ceftriaxone, Trimethoprim-Sulfamethoxazole, } \\
\text { or Ciprofloxacin }\end{array}$ & $\begin{array}{l}\text { Local resistance data should be consulted. } \\
\text { Avoid fluoroquinolones if }>10 \% \text { resistance } \\
\text { prevalence or trimethoprim-sulfamethoxazole } \\
\text { in areas of high resistance }\end{array}$ \\
\hline
\end{tabular}

\section{Centeral Nervous System}

\begin{tabular}{|c|c|c|}
\hline Meningitis & Vancomycin cefftriaxone & $\begin{array}{l}\text { In the elderly and immunocompromised, add } \\
\text { Ampicillin Penetrating head trauma, CSF } \\
\text { shunt or postneurosurgery vancomycin and } \\
\text { cefepime, ceftazidime or meropenem }\end{array}$ \\
\hline
\end{tabular}




\section{Dermatological}

Necrotizing fasciitis, Purulent furuncle/carbuncle/abscess Nonpurulent, cellulitis/erysipelas
Multidrug therapy with vancomycin or linezolid and piperacillin-tazobactam, a carbapenem, or ceftriaxone and metronidazole
Do not delay incision and drainage where indicated.

\section{Methicillin Resistant Staphylococcus Aureus MRSA}

\section{Other Supportive Care to Prevent Progression to Organ Damage}

a) Ensure adequate oxygenation by maintaining oxygen saturation $\geq 92 \%$

b) Maintain $\mathrm{Hb} \geq 7 \mathrm{~g} / \mathrm{dl}$

c) Ensure patient receives prophylaxis for venous thromboembolism (VTE)

d) Consider the use of proton pump inhibitors for stress ulcer prophylaxis

e) Ensure adequate nutrition and monitor blood glucose closely. Avoid hypoglycemia.

f) Maintain oral, vulva and anal hygiene.

\section{Conclusion}

The management of sepsis is complex and clinical approaches to managing a septic patient continue to advance. However, early detection and initiation of therapy is important in reducing the mortality from sepsis. To achieve the desired outcome, a sustained as well as collaborative quality improvement across different specialties of medicine is required.

\section{Author's Contribution}

Conceptualization: Adamu S. Abubakar, Buma G.B, Ballah Abubakar, Usman S Panda.

Draft Preparation: Hassan Maina, Ballah Abubakar, Jimoh L Mufutahu, Dakum Lonji.

Proof Reading and Approval of Final Manuscript: All Authors.

\section{Conflict of Interest}

None to declare.

\section{Funding}

Federal Ministry of Health, Nigeria.

\section{References}

1. Bone C, Balk RA, Cerra FB, RP Dellinger, AM Fein, et al. (1992) Definitions for sepsis and organ failure and guidelines for the use of innovative therapies in sepsis. The ACCP/SCCM consensus conference committee American college of chest physicians/ society of critical care medicine. Chest 101: 1644-1655.

2. Levy MM, Fink MP, Marshall JC, Abraham E, Angus D, et al. (2003) 2001 SCCM/ESICM/ACCP/ATS/SIS International Sepsis Definitions Conference. Intensive Care Med 29: 530-538.

3. Singer M, Deutschman CS, Seymour CW, Hari MS, Annane D, et al. (2016) The Third International Consensus Definitions for Sepsis and Septic Shock (Sepsis-3). JAMA 315: 801-810.

4. Levy MM, Rhodes A, Phillips GS, Townsend SR, Schorr CA, et al. (2015) Surviving Sepsis Campaign: Association between performance metrics and outcomes in a 7.5-Year study. Crit Care Med 43: 3-12.

5. ProCESS Investigators, Yealy DM, Kellum JA, Huang DT, Barnato AE, et al. (2014) A Randomized Trial of Protocol-Based Care for Early Septic Shock N Engl J Med 370: 1683-1693.

6. McGaughey J, O'Halloran P, Porter S, Blackwood B (2017) Early warning systems and rapid response to the deteriorating patient in hospital: A systematic realist review. J Adv Nurs 73: 2877-2891.

7. (2017) Royal College of Physicians. National Early Warning Score (NEWS) 2: Standardizing the Assessment of Acute-illness Severity in the NHS. Updated report of a working party. London: RCP.

8. Rhodes A, Evans LE, Alhazzani W, Levy MM, Antonelli M, et al. (2017) Surviving Sepsis Campaign: International Guidelines for Management of Sepsis and Septic Shock: 2016. Intensive Care Med 43: 304-377.

9. Prescott HC, Iwashyna TJ (2019) Improving sepsis treatment by embracing diagnostic uncertainty. Ann Am Thorac Soc 16: 426-429.

10. Cressman AM, MacFadden DR, Verma AA, Razak F, Daneman N (2019) Empiric antibiotic treatment thresholds for serious bacterial infections: A scenario-based survey study. Clin Infect Dis 69: 930-937. 